\title{
The sonic hedgehog signaling pathway stimulates anaplastic thyroid cancer cell motility and invasiveness by activating Akt and c-Met
}

\author{
Ashley J. Williamson ${ }^{1}$, Michelle E. Doscas ${ }^{2}$, Jin $\mathrm{Ye}^{2}{ }^{2}$ Katherine B. Heiden ${ }^{3}$, Mingzhao \\ $\mathbf{X i n g}^{4}, \mathbf{Y i ~ L i}^{5}$, Richard A. Prinz ${ }^{6}$ and Xiulong $\mathbf{X u}^{7,2,3}$ \\ ${ }^{1}$ Rush Medical College, Rush University Medical Center, Chicago, IL, USA \\ 2 Department of Anatomy and Cell Biology, Rush University Medical Center, Chicago, IL, USA \\ ${ }^{3}$ Department of General Surgery, Rush University Medical Center, Chicago, IL, USA \\ ${ }^{4}$ Division of Endocrinology and Metabolism, Department of Medicine, The Johns Hopkins University School of Medicine, \\ Baltimore, MD, USA \\ ${ }^{5}$ Lester and Sue Smith Breast Center and Department of Molecular and Cell Biology, Baylor College of Medicine, Houston, \\ TX, USA \\ ${ }^{6}$ Department of Surgery, NorthShore University Health System, Evanston, IL, USA \\ ${ }^{7}$ Center for Comparative Medicine, College of Veterinary Medicine, Yangzhou University, Yangzhou, Jiangsu Province, China \\ Correspondence to: Xiulong XU, email: $x x \mid @ y z U . e d u . c n$ \\ Keywords: sonic hedgehog signaling pathway, PI-3 kinase, c-Met, Snail, cell motility and invasion \\ Received: August 03, $2015 \quad$ Accepted: January 27, $2016 \quad$ Published: February 07, 2016
}

\section{ABSTRACT}

The sonic hedgehog (Shh) pathway is highly activated in thyroid neoplasms and promotes thyroid cancer stem-like cell phenotype, but whether the Shh pathway regulates thyroid tumor cell motility and invasiveness remains unknown. Here, we report that the motility and invasiveness of two anaplastic thyroid tumor cell lines, KAT-18 and SW1736, were inhibited by two inhibitors of the Shh pathway (cyclopamine and GANT61). Consistently, the cell motility and invasiveness was decreased by Shh and Gli1 knockdown, and was increased by Gli1 overexpression in KAT-18 cells. Mechanistic studies revealed that Akt and c-Met phosphorylation was decreased by a Gli1 inhibitor and by Shh and Gli1 knockdown, but was increased by Gli1 overexpression. LY294002, a PI-3 kinase inhibitor, and a c-Met inhibitor inhibited the motility and invasiveness of Gli1-transfected KAT-18 cells more effectively than the vector-transfected cells. Knockdown of Snail, a transcription factor regulated by the Shh pathway, led to decreased cell motility and invasiveness in KAT-18 and SW1736 cells. However, key epithelial-to-mesenchymal transition (EMT) markers including E-cadherin and vimentin as well as Slug were not affected by cyclopamine and GANT61 in either SW1736 or WRO82, a well differentiated follicular thyroid carcinoma cell line. Our data suggest that the Shh pathway-stimulated thyroid tumor cell motility and invasiveness is largely mediated by AKT and c-Met activation with little involvement of EMT.

\section{INTRODUCTION}

In mammals, the hedgehog pathway is regulated by three ligands: Sonic hedgehog (Shh), Indian hedgehog, and Desert hedgehog. In the absence of these ligands, the Shh pathway is inactive since the transmembrane receptor, Patched (Ptch) functions as a tumor suppressor to prevent Smoothened (Smo), a G-protein coupled receptor [1-3] from activating a family of oncogenic Gli transcription factors. Hedgehog binding to Patched leads to the uncoupling of Patched from Smo, subsequently leading to the activation of a signal cascade and the translocation of Gli into the nucleus to induce or repress gene expression [1-3].

The sonic hedgehog signaling pathway has been implicated in stimulating tumor cell motility and invasion 
in several types of malignancies [3]. One of the Gli1regulated genes, SNAIL, can function as a transcription repressor for E-cadherin [4]. Loss of E-cadherin is a hallmark of the epithelial to mesenchymal transition (EMT). Intriguingly, Gli1 can directly bind the E-cadherin promoter and induce its expression $[5,6]$. Whether the Shh pathway stimulates tumor cell invasiveness through EMT remains controversial. In addition, the Shh pathway may promote tumor cell invasiveness by cross-activating the PI-3 kinase pathway or induces metalloproteinase expression [7-15]. Disregulated Shh signaling correlates with the severity of the associated tumor and contributes to maintain metastatic behavior. Understanding the crosstalk between the Shh and other pathways will facilitate the discovery of novel therapeutics and the treatment of metastatic disease.

Improved understanding of genetic alterations such as identification of high frequency BRAF gene mutations in thyroid cancer offers new hope for promising target therapy. Undifferentiated anaplastic thyroid carcinoma (ATC) is almost always fatal, with a mean survival of 6 months [16]. However, significant challenges remain as drug resistance arises due to the transactivation of other signaling pathways or new gene mutations in the same pathway. Recent studies have identified thyroid cancer stem cells (CSCs) as a unique population (about $1-3 \%$ ) that is highly tumorigenic and metastatic. Poorly differentiated or undifferentiated thyroid cancers contain a higher percentage of ALDH (aldehyde dehyrogenase)positive CSCs than benign adenomas and well differentiated thyroid cancers. CSC-enriched ATC is highly invasive and metastatic due to hyperactivation of the PI-3 kinase pathway and c-Met [17, 18]. We and others have demonstrated that the Shh pathway is widely activated in thyroid neoplasm and promotes thyroid tumor cell proliferation [19-22]. Our further studies showed that the Shh pathway promotes the cancer stem-like cell phenotype of two anaplastic thyroid carcinoma cell lines, KAT-18 and SW1736 [23]. Here we report that the Shh pathway plays an important role in the tumor cell motility and invasiveness of anaplastic thyroid cancer cell lines by activating c-Met and AKT.

\section{RESULTS}

\section{Effect of the Shh pathway on thyroid tumor cell motility and invasiveness}

We first examined the effect of cyclopamine, a Smo inhibitor, and GANT61, a Gli1 inhibitor, on the motility and invasiveness of KAT-18 and SW1736 cells. As shown in Figure 1A, cyclopamine and GANT61 decreased KAT-18 cell motility by $54 \%$ and $76 \%$, respectively, and inhibited the invasive potential of KAT-18 cells by
$24 \%$ and $66 \%$, respectively. Cyclopamine and GANT61 inhibited the motility of SW1736 cells by $73 \%$ and $79 \%$, respectively, and inhibited the invasive potential of SW 1736 cells by $47 \%$ and 38\%, respectively (Figure 1B). According to our prior study [19], SW1736 cells are resistant to the anti-proliferative effect of cyclopamine, whereas KAT-18 cells are sensitive to cyclopamine, with the inhibition of cell proliferation by $50 \%$ after incubation $96 \mathrm{hr}$. The inhibitory effect of cyclopamine and GANT61 on cell motility and invasiveness was not due to their inhibitory effect on cell proliferation since the experiments were carried out overnight, the antiproliferative effect after such a short duration is minimal and almost neglectable, in particular for SW1736 cells. KAT-18 and SW1736 cells were readily attached onto the uncoated or Matrigel-coated inserts in the absence or presence of cyclopamine or GANT61 $2 \mathrm{hr}$ after seeding. Neither cyclopamine nor GANT61 interfered with the adhesion of these two cell lines.

We reported earlier that two miRNA constructs targeting Shh and Glil were very effective at suppressing Shh and Gli1 expression in either transiently [19] or stably [23] transfected KAT-18 cells. We repeated Western blot analysis and again demonstrated the ability of these miRNA constructs to suppress Shh and Gli1 in KAT-18 cells stably transfected with these miRNA constructs (Figure 2A). Consistent with our earlier observation [23], we found that Shh knockdown in KAT-18 cells stably transfected with Shh-miRNA led to a modest decrease of Gli1 expression, probably due to an autocrine regulation by the Shh pathway (Figure 2A). Our recent study demonstrated the ability of pcDNA/Glil vector to overexpress Gli1 in stably transfected KAT-18 cells [23]. Again we confirmed Gli1 overexpression in pcDNA/Gli1transfected KAT-18 cells (Figure 2B). Cell motility of Shh-miRNA- and Gli1-miRNA-transfected KAT-18 cells was decreased by $47 \%$ and $42 \%$, respectively, and their invasive potential reduced by $76 \%$ and $53 \%$, respectively (Figure 2C). In contrast, Gli1 overexpression in pcDNA/ Gli1-transfected KAT-18 cells led to increased cell motility and invasiveness by $43 \%$ and $560 \%$, respectively (Figure 2D).

\section{Induction of AKT and c-Met phosphorylation by the Shh pathway and the consequence on cell motility and invasiveness}

The Shh pathway is implicated in promoting the cancer stem-like cell type of anaplastic thyroid cancer cell lines [23]. c-Met and AKT are highly phosphorylated and activated in invasive thyroid CSC [17]. Here we tested whether inhibition of the Shh pathway by two inhibitors led to decreased c-Met and AKT phosphorylation. Cyclopamine had little effect on c-Met and AKT phosphorylation in KAT-18 (Figure 3A) but did inhibit 


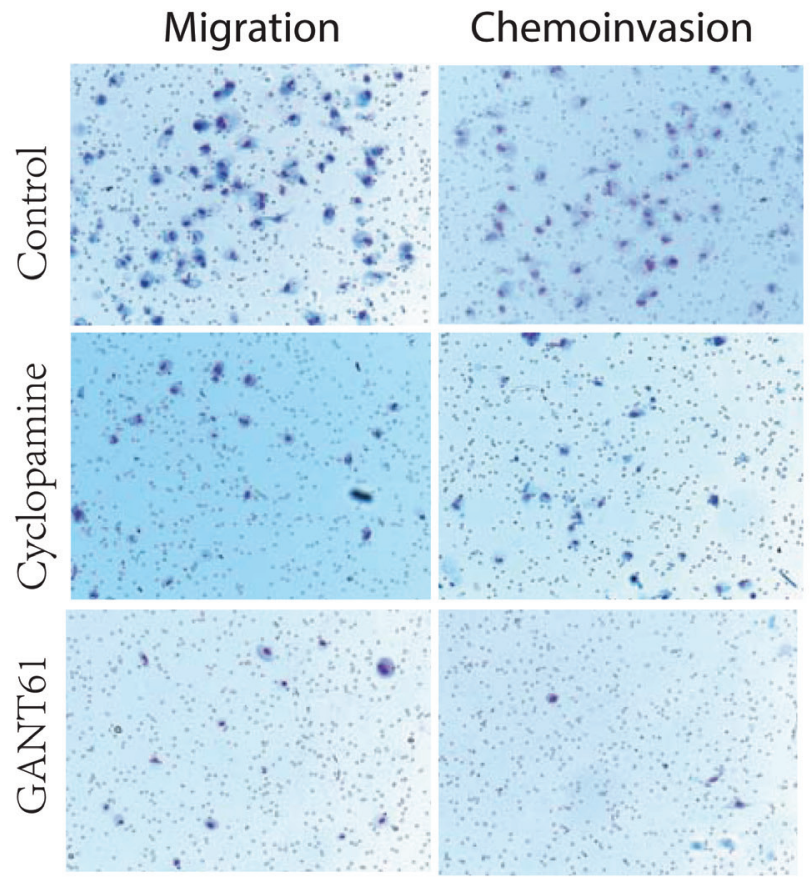

KAT-18

B

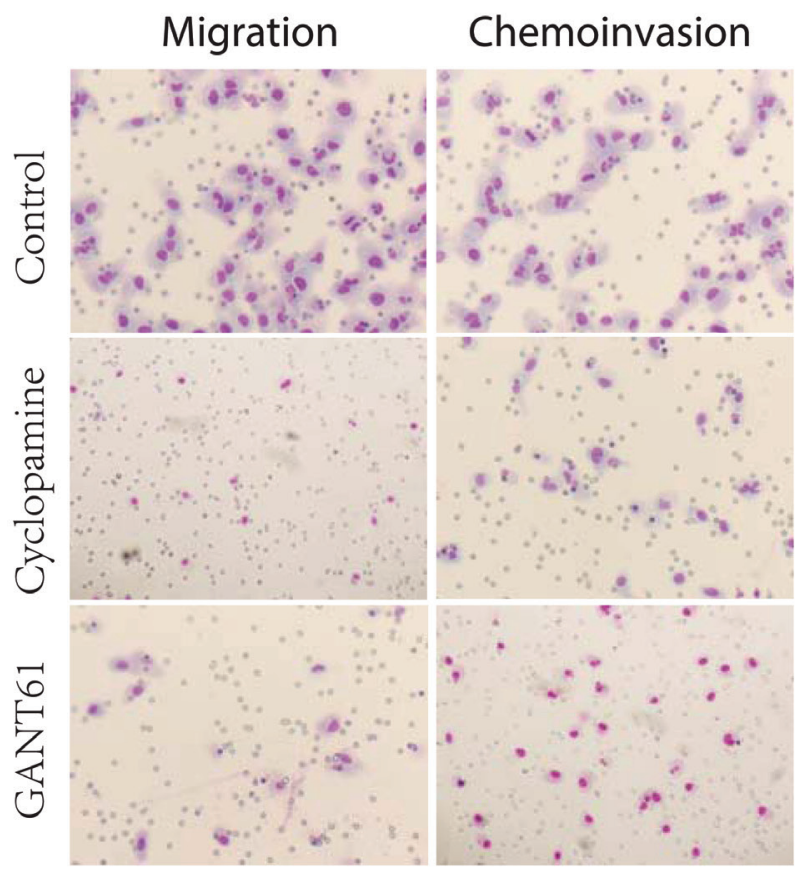

SW1736
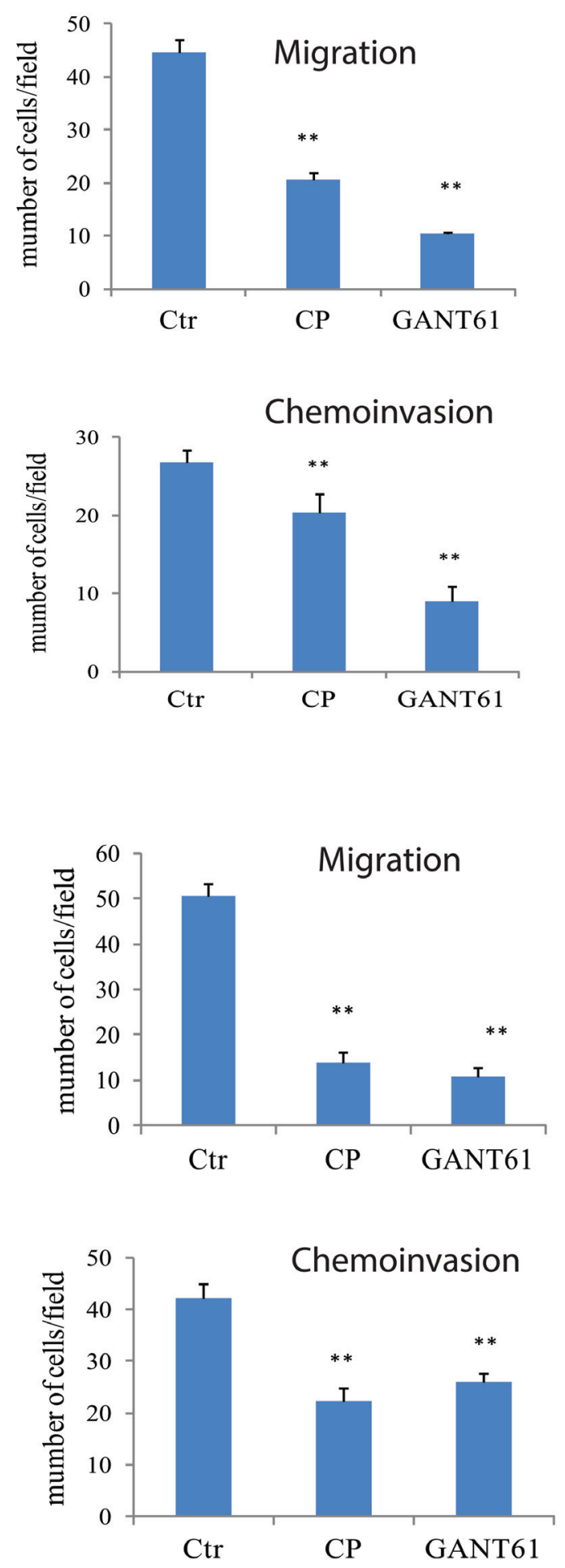

Figure 1: Inhibition of the Shh pathway leads to reduced cell motility and invasive potential. KAT-18 A. and SW1736 B. seeded in uncoated or Matrigel-coated Boyden chambers in duplicate were incubated for $24 \mathrm{hr}$ in the presence of $0.5 \%$ DMSO, cyclopamine $(5 \mu \mathrm{M})$ or GANT61 $(10 \mu \mathrm{M})$. Cells migrating through the pored PET membrane were stained in Diff-Quik solutions. Data represent the mean \pm SD of the numbers of the cells in five random fields (10X) in duplicate. The experiment was repeated at least twice with similar results. ${ }^{*} p<0.05 ; * p<0.01$. 

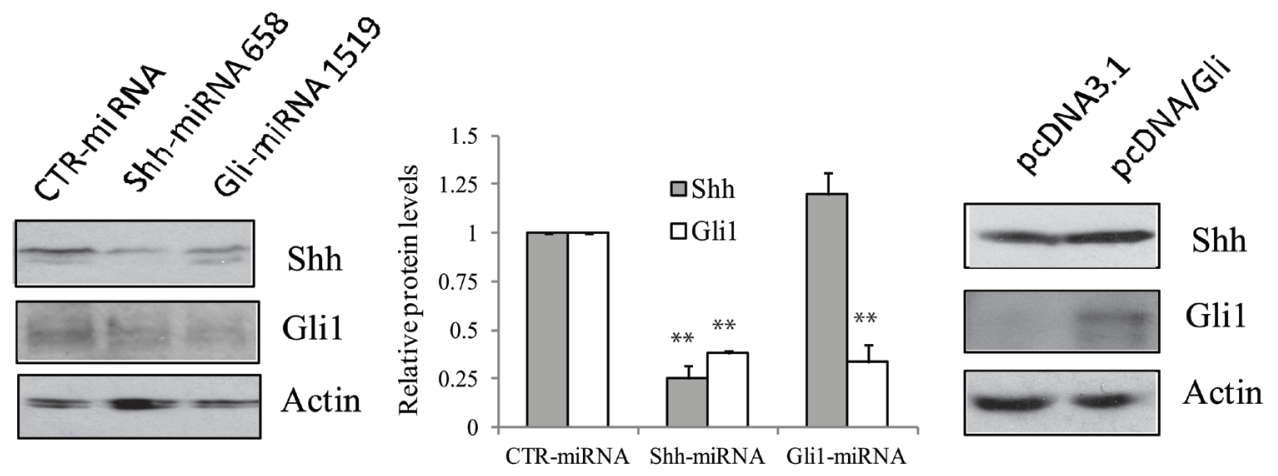

C
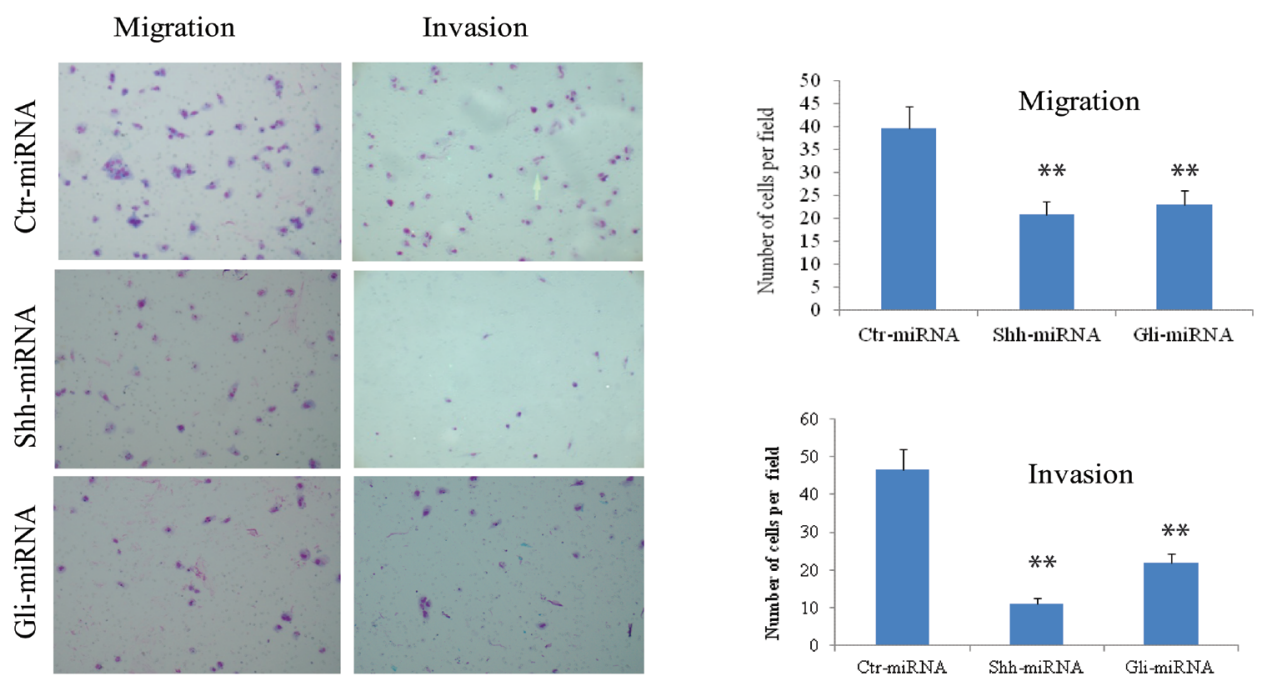

D
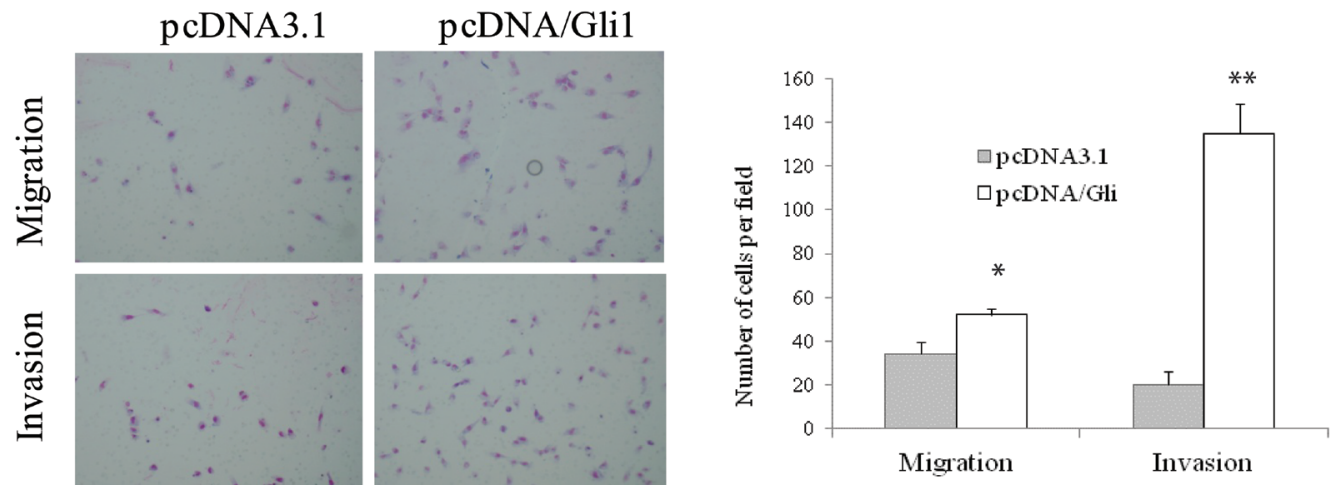

Figure 2: Effect of the Shh pathway knockdown or Gli1 overexpression on cell motility and invasiveness. (A \& B) KAT18 cells stably transfected with an expression vector encoding a control, Shh or Gli1 miRNA A. or transfected with pcDNA3.1 or pcDNA/ Gli1 B. were analyzed for Shh and Gli1 expression by Western blot with their specific antibodies. Actin was included as a loading control. The density of the bands was analyzed by using an NIH Image-J software and normalized by the arbitrary units of the density of actin. The results were the mean \pm standard deviation from three independent experiments. C \& D. Effect of the Shh pathway on cell motility and invasiveness. KAT-18 cells stably transfected with control miRNA, Shh-miRNA 658 or Gli-miRNA 1519 C. or KAT-18 cells transfected with pcDNA3.1 or pcDNA/Gli1 D. were seeded in uncoated or Matrigel-coated Boyden chambers and for their migratory and invasive potential after incubation for $24 \mathrm{hr}$. Data represent the mean $\pm \mathrm{SD}$ of the numbers of the cells in five random fields $(10 \mathrm{X})$ in duplicate. Data represent the results of one of two experiments with similar results. ${ }^{*} p<0.05 ;{ }^{* *} p<0.01$. 
c-Met phosphorylation in SW1736 cells (Figure 3B). GANT61 significantly inhibited AKT phosphorylation at Ser-473 in both SW1736 and KAT-18 cells (Figure 3A and

A

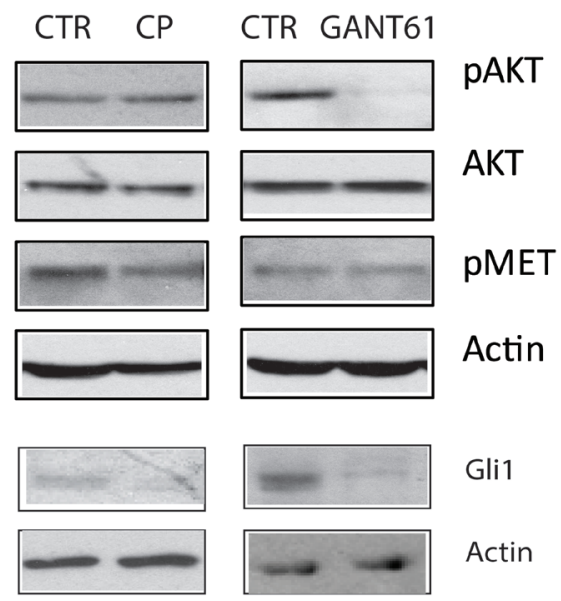

KAT-18

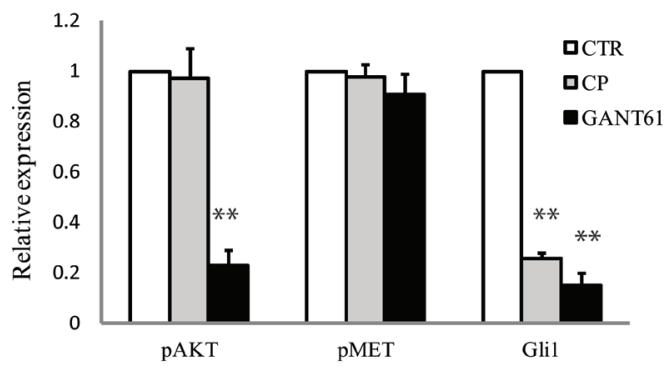

C

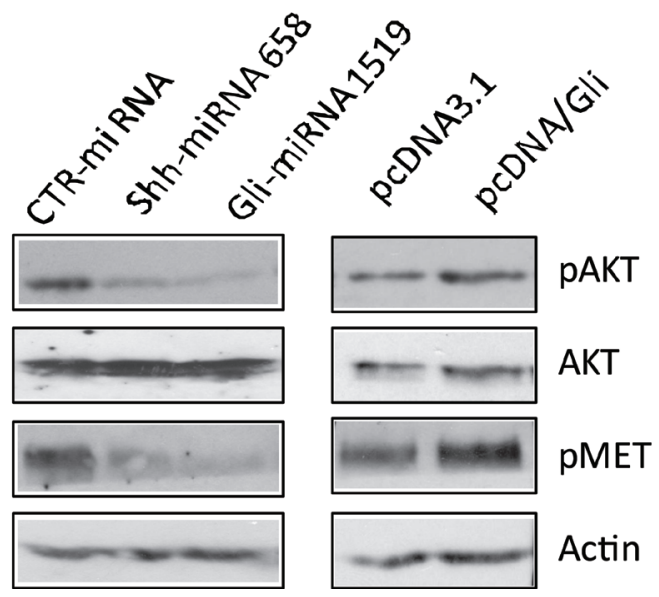

Figure 3: Effect of the Shh pathway on c-Met and AKT phosphorylation. KAT-18 A. and SW1736 B. cells were treated with $0.5 \%$ DMSO, cyclopamine $(5 \mu \mathrm{M})$ or GANT61 $(10 \mu \mathrm{M})$ for $72 \mathrm{hr}$. The cells were harvested and analyzed for AKT (S473) phosphorylation, c-Met tyrosine phosphorylation at Y1230/1234/1235m and Gli1 expression by Western blot with their specific antibodies. The density of the bands from three independent experiments was analyzed and plotted in a bar graph. ${ }^{*} p<0.05 ; * * p<0.01$. C. KAT- 18 cells stably transfected with encoding a control, Shh or Gli1 miRNA or transfected with pcDNA3.1 or pcDNA/Gli1 were analyzed for AKT and c-Met phosphorylation by Western blot with their specific antibodies. Actin was included as a loading control.
3B). It also inhibited c-Met phosphorylation at tyrosine residues (Y1230/1234/1235) in SW1736 cells (Figure 3B) but had little effect in KAT-18 cells (Figure 3A).

B

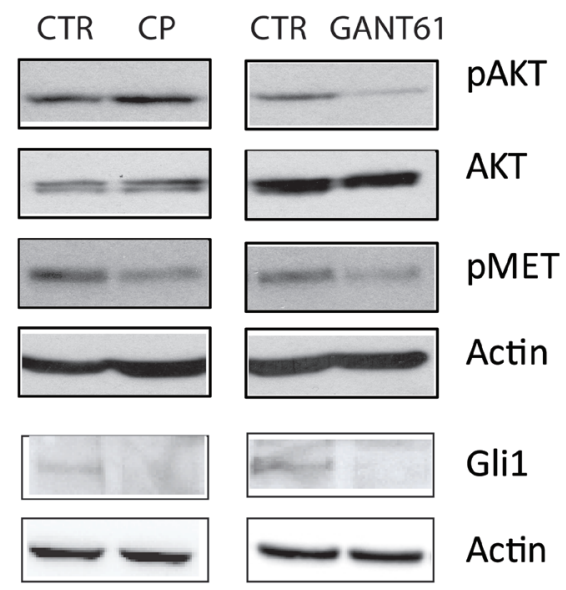

SW1736

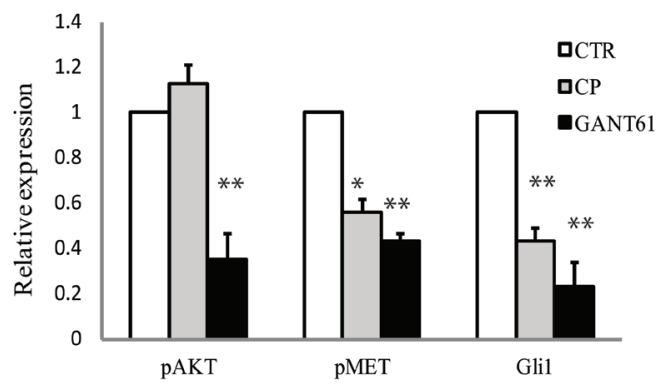


A

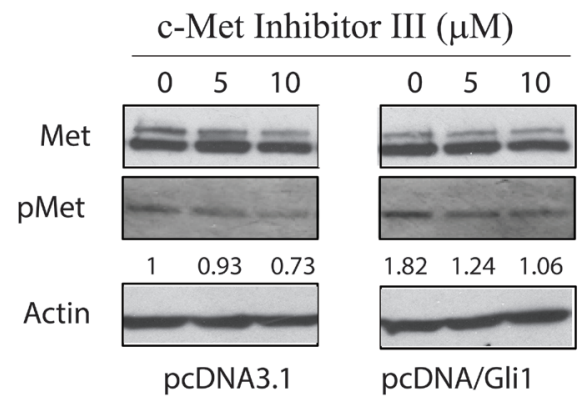

C

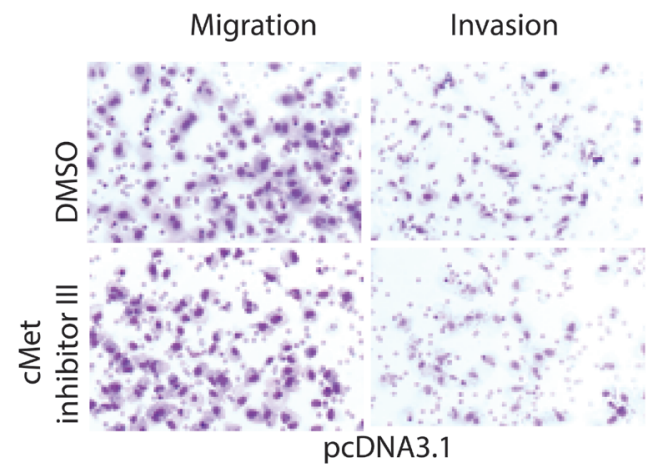

$E$

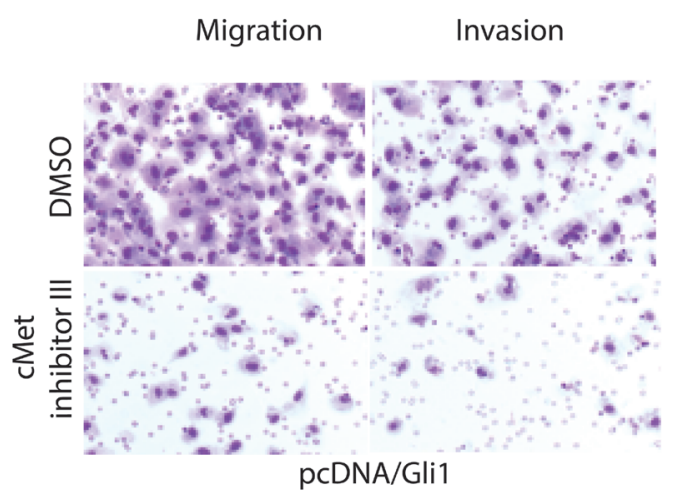

G

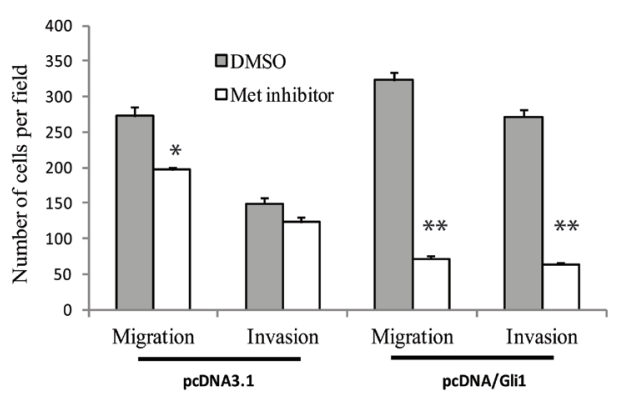

B

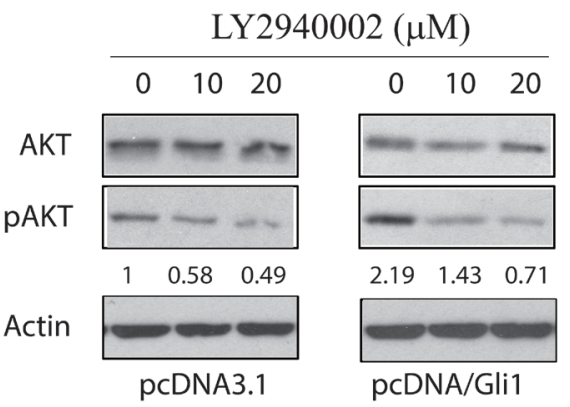

D

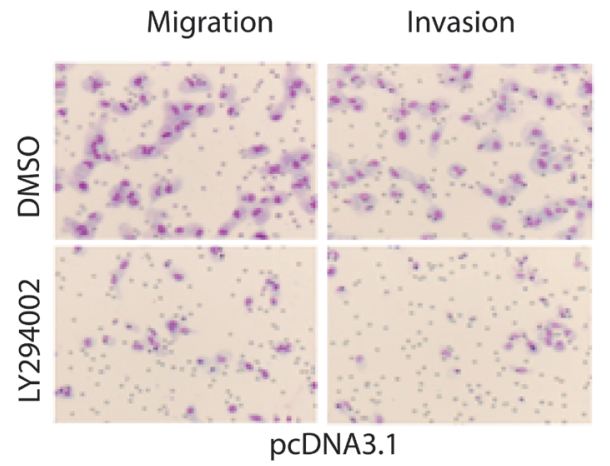

$\mathrm{F}$
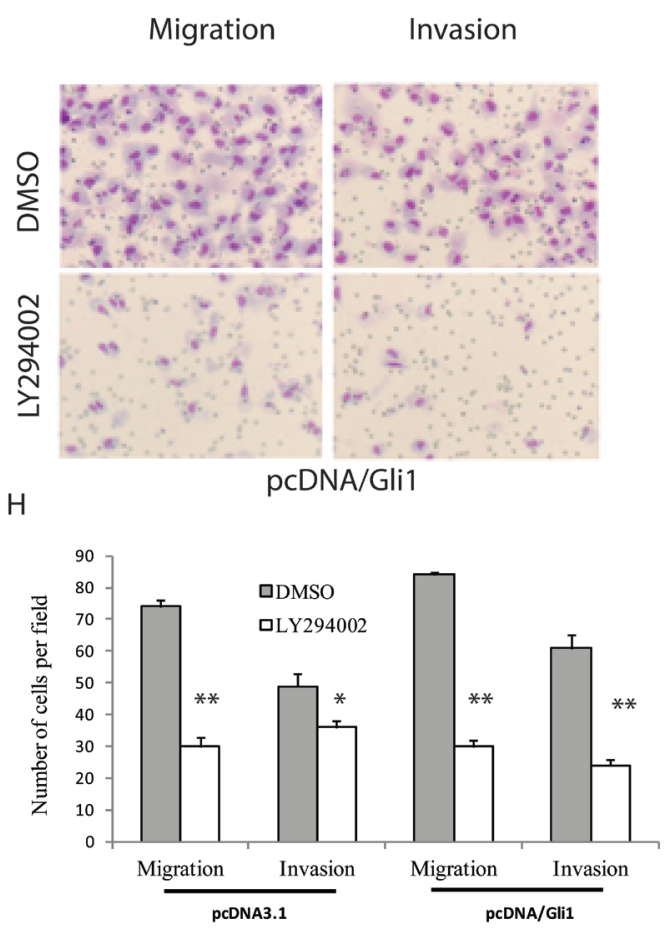

Figure 4: AKT and c-Met activation is required for the Shh pathway-induced cell motility and invasiveness. pcDNA3.1 and pcDNA/Gli1-transfected KAT-18 cells seeded in 6-well plates were treated with a c-Met inhibitor III A. or an AKT inhibitor LY294002 B. with indicated concentrations for $24 \mathrm{hr}$. Cells were harvested and analyzed for c-Met tyrosine phosphorylation and AKT S473 phosphorylation by Western blot. The density of the bands was quantified by using an Image-J software and normalized by the arbitrary units of the density of actin. The numbers beneath the blots are a representative of two independent experiments with similar results. C.H. Effect of c-Met inhibitor III and LY294002 on cell migration and invasiveness. pcDNA3.1 (C \& D) and pcDNA/Gli1-transfected (E \& F) KAT-18 cells seeded in Boyden chambers were incubated in the presence of DMSO $(0.5 \%)$, c-Met inhibitor III $(5 \mu \mathrm{M})(\mathrm{C} \& \mathrm{E})$ or LY294002 $(10 \mu \mathrm{M})(\mathrm{D} \& \mathrm{~F})$ for $24 \mathrm{hr}$. The cells migrating through the pored PET membrane were stained using Diff-Quik solution. The data represent the mean $\pm \mathrm{SD}$ of the numbers of the cells in five random fields $(10 \mathrm{X})$ in duplicate $(\mathrm{G} \& \mathrm{H})$. Experiments were repeated at least twice with similar results. The experiment was repeated twice with similar results. ${ }^{*} p<0.05 ;{ }^{* *} p<0.01$. 
Cyclopamine and GANT61 both inhibited Gli1 expression in KAT-18 and SW1736 cells (Figure 3A and 3B). Shh and Gli1 knockdown significantly decreased AKT and c-Met phosphorylation (Figure 3C), whereas Gli1 overexpression modestly increased AKT and c-Met phosphorylation in KAT-18 cells, compared to pcDNA3.1-transfected cells (Figure 3C).

A

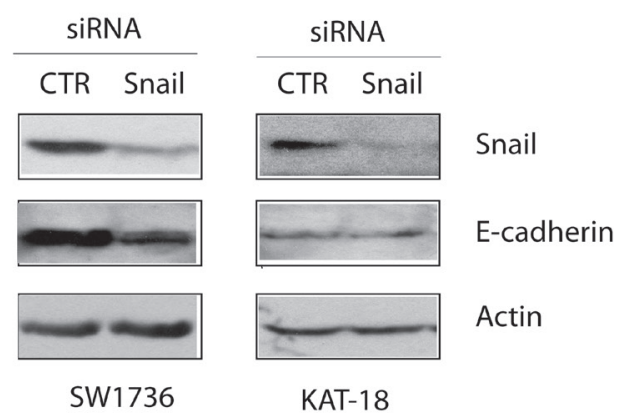

B

C

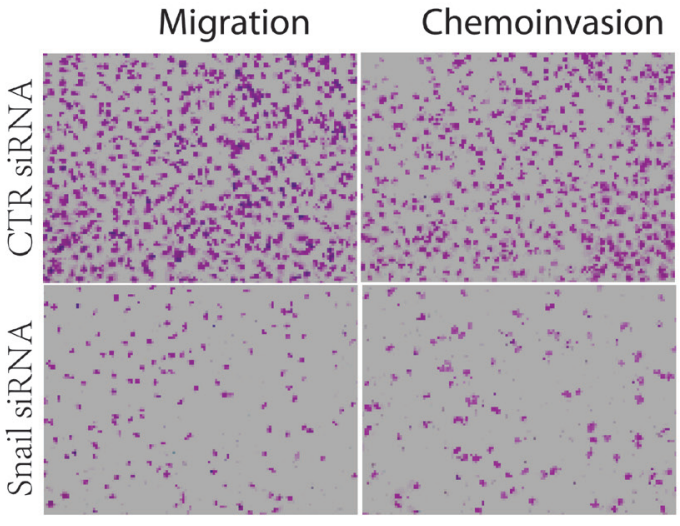

SW1736

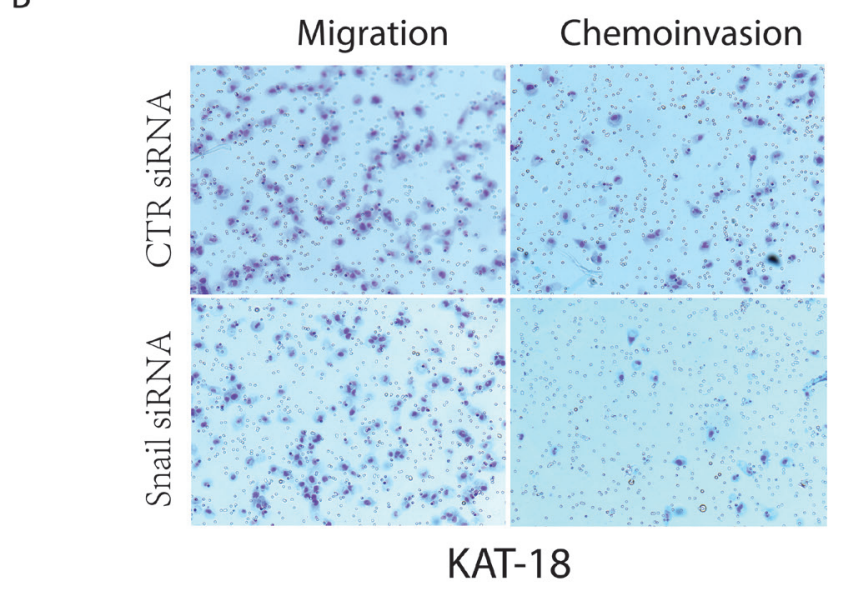

KAT-18
We next determined if c-Met and AKT were required for the Shh pathway-induced cell motility and invasiveness. First, we found that the inhibitors of c-Met and AKT were able to inhibit c-Met tyrosine (Figure 4A) and AKT S473 (Figure 4B) phosphorylation in pcDNA3.1and pcDNA/Gli1-transfected KAT-18 cells in a dosedependent manner, respectively. c-Met kinase inhibitor
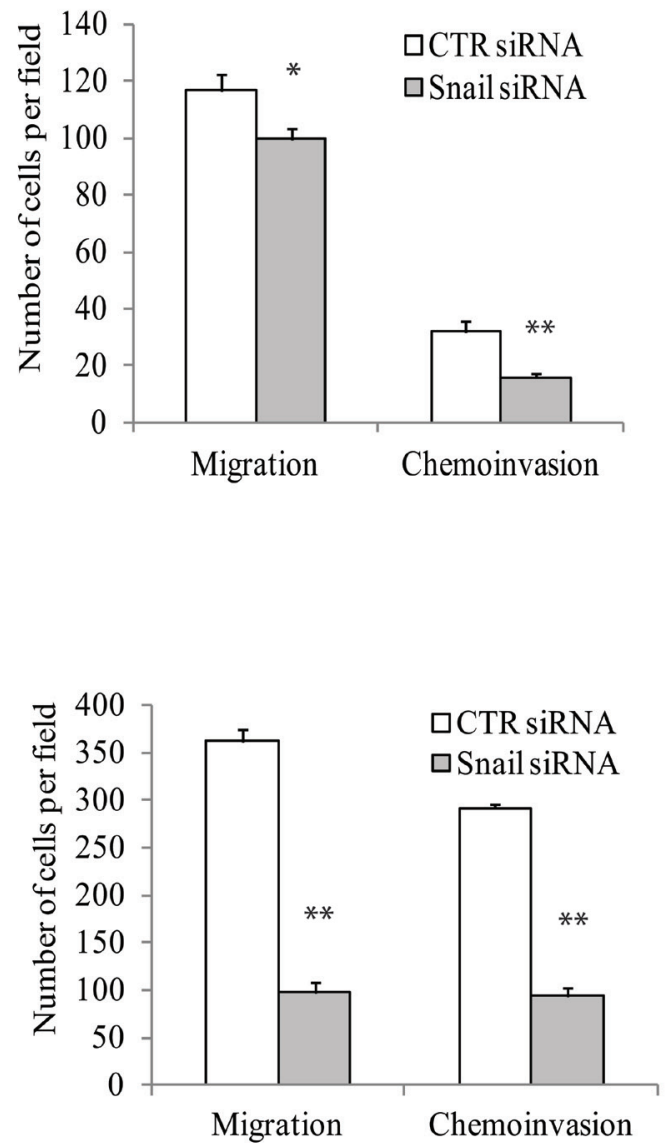

Figure 5: Snail knockdown inhibits cell motility and invasiveness. KAT-18 and SW1736 cells seeded in 35-mm dishes were transfected with a scrambled control siRNA or Snail siRNA (2.5 nmole each). After incubation for $48 \mathrm{hr}$, the cells were harvested and analyzed for Snail and actin expression by Western blot A. or for cell motility and invasiveness of KAT-18 B. and SW1736 cells C. in uncoated or Matrigel-coated Boyden chamber. Data represent the results of one of two independent experiments with similar results. ${ }^{*} p<$ $0.05 ; * *<0.01$. 
III decreased the motility and invasiveness of pcDNAtransfected KAT-18 cells by $28 \%$ and $17 \%$ respectively, and inhibited the motility and invasive potential of Gli1transfected KAT-18 cells by $78 \%$ and $77 \%$ respectively (Figure 4G). LY294002, an AKT inhibitor, decreased the motility and invasiveness of pcDNA-transfected KAT-18 cells by $60 \%$ and $27 \%$ respectively, and the motility and invasive potential of Gli1-transfected KAT-18 cells by $64 \%$ and $61 \%$, respectively (Figure $4 \mathrm{H}$ ). Of note, c-Met inhibitor III weakly inhibited KAT-18 cell migration but did not significantly inhibit invasiveness (Figure 4G). This is likely due to low basal level c-Met phosphorylation and activation in KAT-18 cells (Figure 6B)

\section{Role of Snail in thyroid tumor cell motility and invasiveness}

Since Snail is tightly regulated by the Shh pathway, and Snail has been implicated in tumor cell metastasis in an EMT-dependent and -independent manner [24, 25], we tested if Snail was involved in regulating thyroid tumor cell motility and invasiveness. As shown in Figure 5A, Snail expression was effectively suppressed in KAT18 and SW1736 cells transfected with Snail siRNA. Unexpectedly, Snail knockdown had no or little inhibitory effect on E-cadherin expression. Snail knockdown decreased KAT-18 cell motility and invasiveness by $15 \%$ and $50 \%$, respectively (Figure 5B), and more effectively decreased SW1736 cell motility and invasiveness by $83 \%$ and $67 \%$, respectively (Figure 5C). The differential sensitivity of KAT-18 and SW1736 cells to Snail suppression-mediated inhibition of cell motility and invasiveness is likely due to differential Snail expression in these two cell lines (Figure 6A).

\section{Role of the Shh pathway in EMT}

We first tested if the Snail levels in 5 thyroid tumor cell lines inversely correlated with E-cadherin expression. Western blot analysis revealed that E-cadherin was expressed at high levels in WRO82 cells but at very low levels in four other cell lines (KAT-18, SW1736, TPC1, and BCPAP) (Figure 6A). Snail was expressed at relatively low levels in WRO82 cells but was expressed in four other cell lines, in particular in SW1736 cells. AKT was highly phosphorylated at S473 in KAT-18 cells, whereas c-Met tyrosine phosphorylation was very low in this cell line (Figure 6B). It appears that there was no correlation between Snail expression and AKT/cMet phosphorylation (Figure 6A and 6B). Suppression of the Shh pathway by Shh and Glil knockdown weakly increased E-cadherin expression, whereas Gli1 overexpression slightly decreased E-cadherin expression (Figure 6C). Unexpectedly, cyclopamine and GANT61 slightly decreased or had no effect on E-cadherin expression (Figure 6D) in KAT-18 cells. Cyclopamine and GANT61 all drastically inhibited Snail expression in a dose-dependent manner in SW1736 cells (Figure 6E) but had relatively weak effect on WRO82 cells, probably due to very low level of Snail expression. These inhibitors had no or minimal effect on E-cadherin, Vimentin, and Slug expression in SW1736 and WRO82 cells (Figure 6E and $6 \mathrm{~F})$.

\section{DISCUSSION}

Our present study showed that inhibition of the Shh pathway by Smo and Gli1 inhibitors or by Shh and Gli1 knockdown led to decreased cell motility and chemoinvasion in KAT-18 and SW1736 cells, whereas Gli1 overexpression enhanced KAT-18 motility and invasive potential. AKT and c-Met phosphorylation was increased in Gli1-transfected KAT-18 cells but decreased in KAT-18 cells with Shh and Gli1 knockdown. c-Met inhibitor III and the AKT inhibitor LY294002 decreased cell motility and invasiveness of Gli1-transfected cells. In particular, c-Met inhibitor III was more effective at inhibiting cell migration and invasion in Gli1-transfected than pcDNA3.1-transfected KAT-18 cells, probably as a result of increased c-Met activation in Gli1-transfected cells (Figure 4A). Our studies suggest that the Shh pathway promotes thyroid tumor cell motility and invasiveness by activating AKT and c-Met. Of note, our prior clinical study did not reveal a correlation between the Shh pathway activation and the invasive potential of thyroid cancer [19]. This is likely due to the noncanonical activation of Gli1 by other pathways such as the MAP kinase pathway due to RAS and BRAF gene mutations [26]. In addition, the activation of the PI-3 and MAP kinase pathways also induces the expression of thrombospondin-1 and EMT-related genes to promote tumor invasion [27-29]. Myopericytoma, a rare tumor with a phenotype of pluripotent stem-cell-like pericytes, is also highly aggressive with recurrent disease [30]. Targeting mutant B-Raf kinase in myopericytoma leads to the inhibition of cell migration, invasion, and angiogenesis [30].

Smo functions as a $\mathrm{G}$ protein-coupled receptor. Activation of G $\beta \gamma$ leads to the activation of PI-3 kinase, whereas inhibition of adenylyl cyclase leads to the inhibition of PKA and in part the activation of Gli1 (Figure 7) [11]. Indeed, N-Shh induces AKT phosphorylation in esophageal and gastric cancer cell lines $[10,31]$. Cyclopamine inhibits AKT phosphorylation in hepacellular [13], esophageal [31], and gastric [10, 31] cancer cell lines. Similar to these observations, our study showed that Shh/Gli1 knockdown and GANT61 were very effective in suppressing AKT phosphorylation in KAT-18 and SW1736 cells, whereas Gli1 overexpression increased AKT phosphorylation in KAT-18 cells. Unexpectedly, we found that cyclopamine inhibited Gli1 
A

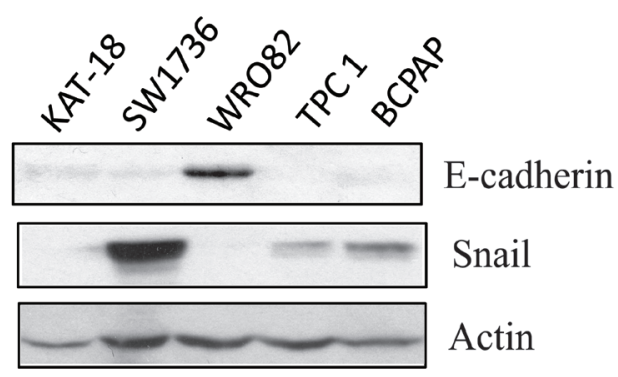

C

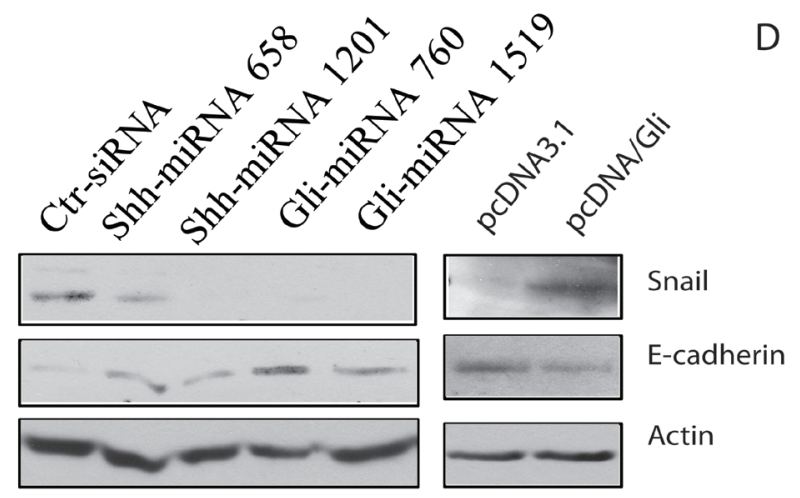

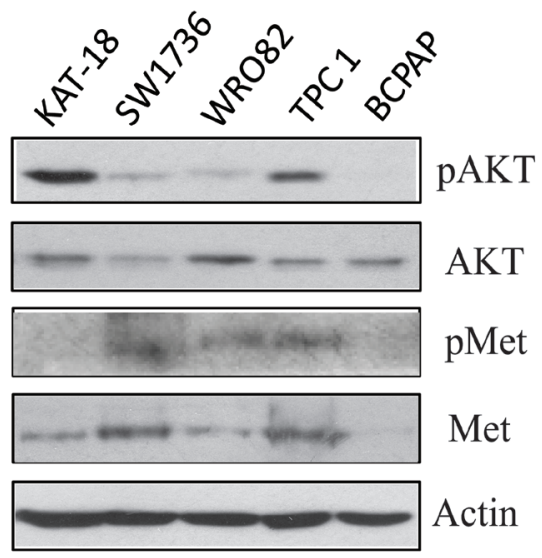

$E$

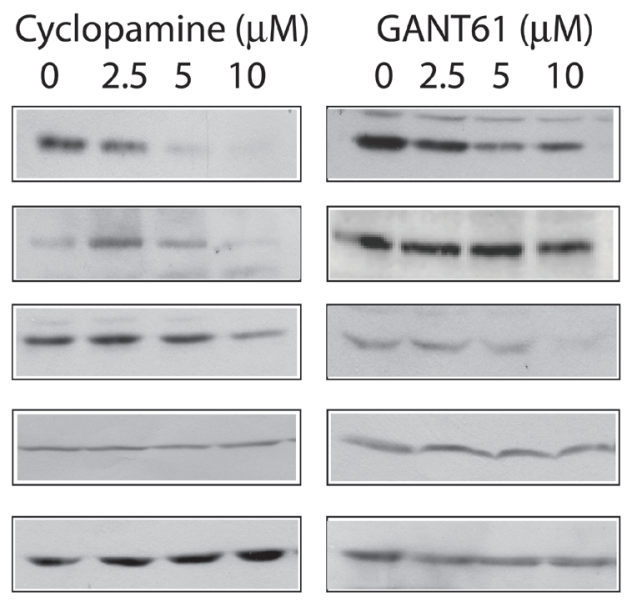

SW1736
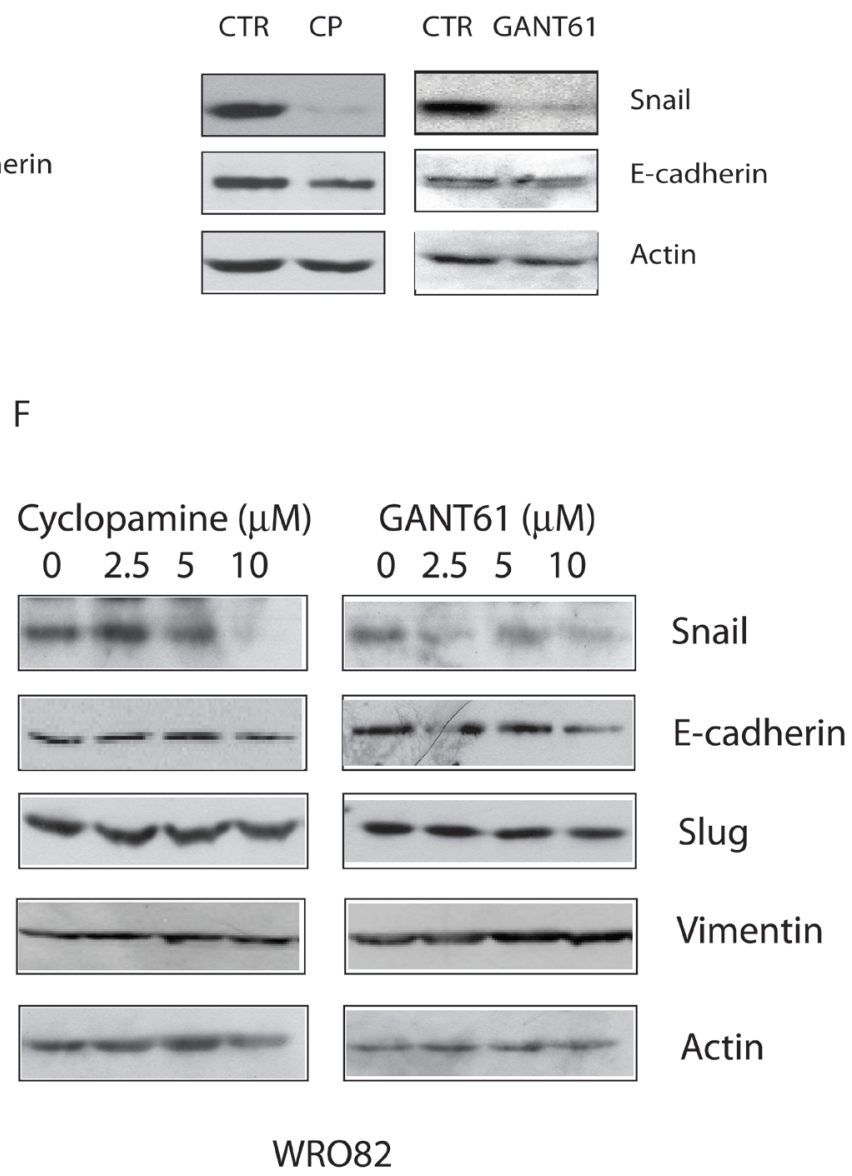

Figure 6: Effect of the Shh pathway on EMT. A. \& B. Cell lysates of KAT-18, SW1736, WRO82, TPC1, and BCPAP cell lines were analyzed for the expression of E-cadherin, Snail, and actin A. or pAKT, AKT, pMet, Met, and actin B. by Western blot. KAT-18 cells stably transfected with an expression vector encoding a control, Shh or Gli1 miRNA C. or transfected with pcDNA3.1 or pcDNA/Gli1 C. were analyzed for E-cadherin expression. (D-F) The effect of the Shh pathway inhibitors on E-cadherin expression. KAT-18 cells D. were treated with $0.5 \%$ DMSO as a vehicle control, cyclopamine $(5 \mu \mathrm{M})$ or GANT61 $(10 \mu \mathrm{M})$ for $72 \mathrm{hr}$. The cells were harvested and analyzed for E-cadherin and actin expression by Western blot with their specific antibodies. SW1736 E. and WRO82 F. cells were incubated in the presence of vehicle $(0.5 \%$ DMSO) or the indicated concentrations of cyclopamine or GANT61 for $72 \mathrm{hr}$. The cells were harvested and analyzed for the expression of several genes involved in EMT. 
expression but had little effect on AKT phosphorylation in KAT-18 and SW1736 cells (Figure 3A and 3B). How cyclopamine lacked the inhibitory effect on AKT phosphorylation is puzzling. One explanation is that many chemotherapeutic drugs are capable of activating the PI-3 and/or MAP kinase pathways [32]. It is not clear whether cyclopamine, a Smo inhibitor, may activate the PI-3 kinase pathway, thus counteracting its inhibitory effect on AKT phosphorylation mediated through inhibiting the Shh pathway. A second possibility is that Glil activation is responsible for AKT phosphorylation. Blocking the Smo activity by cyclopamine cannot prevent non-canonical Gli1 activation. Therefore a Smo inhbitor cannot, whereas a Gli1 inhibitor can inhibit AKT phosphorylation. In support of this notion, Srivastava et al. [15] recently reported that GANT61 inhibits AKT phosphorylation in embryonal and alveolar rhabdomyosarcomas.

We noticed that E-cadherin expression was not consistently regulated under different experimental settings. For example, overexpression of Gli in KAT18 cells led to increased Snail expression and decreased E-cadherin expression. In contrast, Snail knockdown by siRNA did not increase E-cadherin expression in KAT-18 cells (Figure 5A). There are several explanations for this discrepancy: 1) basal level of Snail expression in KAT18 cells was relatively low (Figure 6A). Indeed, Snail knockdown only weakly inhibited KAT-18 cell motility and invasiveness (Figure 5B); 2) Snail suppression by siRNA is transient and incomplete; 3) The E-cadherin promoter is probably highly methylated in anaplastic cell lines [33-35]. Transient suppression of Snail by siRNA is not sufficient to induce E-cadherin expression.

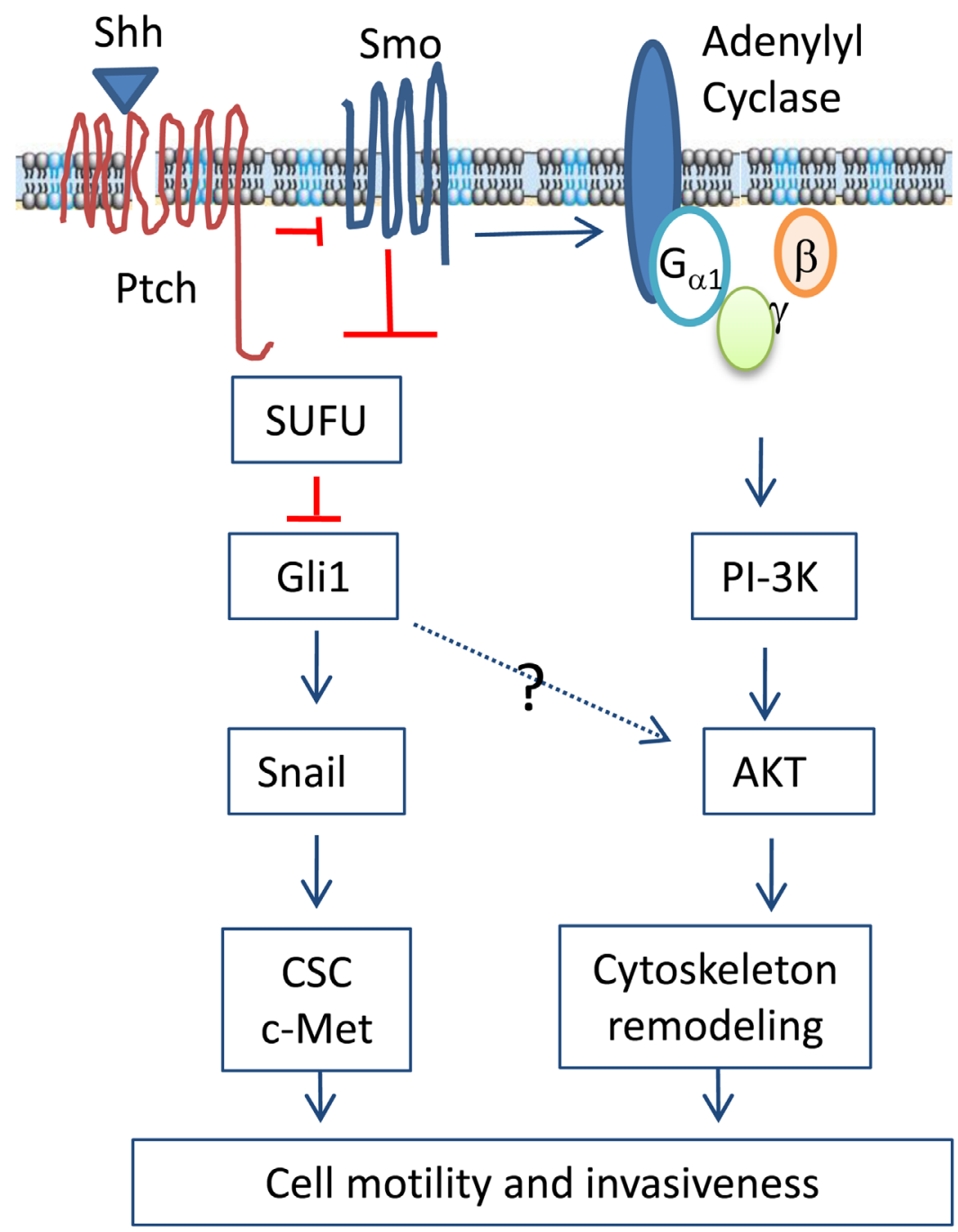

Figure 7: Mechanisms of the Shh pathway-induced cell motility and invasiveness. The binding of Shh to the 12-pass transmembrane receptor Ptch leads to the translocation and activation of Smo, a G protein-coupled receptor. Smo activates Gli1 through inhibiting SUFU, an inhibitors of Gli1. In addition, Smo activation also leads to the formation of the $\mathrm{G}_{\beta}$ and $\mathrm{G}_{\gamma}$ heterodimer, which activates the PI-3-kinase pathway. AKT activation leads to cytoskeleton remodeling and cell motility. Snail expression can be transcriptionally induced by Glil. The Shh pathway may also contribute to increased invasiveness by converting cells to cancer stem-like cell phenotype and c-Met activation. 
We also noticed that drug treatment did not recapitulate the effect of Shh and Gli1 knockdown on E-cadherin expression. There are several explanations again: 1) E-cadherin promoter is highly methylated [3335]. Chronic stable expression of miRNAs that knock down Shh or Gli1 may alter the methylation status of the E-cadherin promoter. In contrast, drug treatments, similar to Snail siRNA, have only transient effect. 2) Nonspecificity of drugs: CP and GANT61, when used at a low concentration, actually increased E-cadherin expression. When they were used at high concentrations, their inhibitory effect on E-cadherin expression could be due to their off-target effect; 3) Regulation of E-cadherin expression is complex. Gli1 and Snail can positively and negatively regulate its promoter activity. Nevertheless, our data consistently showed that stable suppression of Shh and Gli1 expression with miRNA constructs increased E-cadherin expression, whereas Gli1 overexpression in pcDNA/Gli1 stably tranfected cells increased Snail expression and inhibited E-cadherin expression.

The mechanisms by which the Shh pathway stimulates cell motility and invasiveness are complex. Our present study demonstrated that AKT phosphorylation was increased by Gli1 overexpression and decreased by GANT61 or by Shh and Gli1 knockdown in KAT-18 cells. It is well established that Akt phosphorylates several cytoskeleton proteins such as filamin A, pappadin, and vimentin, and that the PI-3 kinase pathway stimulates cell motility in part by cytoskeleton remodeling [36]. Moreover, inhibition of PI-3 kinase by LY294002 led to the inhibition of thyroid tumor cell motility and invasion (Figure 4). We conclude that activation of the PI-3 kinase pathway plays a dominant role in the Shh pathwayinduced cell motility and invasiveness. Consistent with our observations, inhibition of the PI-3 kinase pathway blocks the Shh-pathway-induced tumor cell invasiveness and metastasis of gastric cancer cells [37].

The Shh pathway may also promote tumor cell motility and invasiveness by inducing EMT, a cellular process best characterized by decreased expression of E-cadherin and increased expression of vimentin, fibronectin and N-cadherin. The Shh pathway promotes EMT by inducing Snail expression, leading to E-cadherin expression [38, 39]. For example, the Shh pathway induces EMT in ovarian and pancreatic cancers [40] [5]. Intriguingly, Gli1 itself is able to induce E-cadherin expression through the Gli1-binding site in the E-cadherin promoter $[5,6]$. Thus, E-cadherin can be positively regulated by Gli1 but negatively regulated by Snail. The effect of the Shh pathway on E-cadherin expression is subject to the balance of Gli1 and Snail regulation. Our present study revealed that E-cadherin expression was weakly regulated in KAT-18 cells when the Shh pathway was persistently suppressed or activated through a genetic approach but minimally regulated in three thyroid tumor cell lines by transient inhibition with cyclopamine and GANT61. Liao et al. made similar observations in a SCOV3 ovarian cancer cell line [5]. In addition, we found that the Shh pathway had little effect on the expression of several other EMT-related genes such as vimentin, N-cadherin, and fibronectin. These results suggest that blockade of the Shh pathway was unable to reverse EMT in two anaplastic cell lines, and that the Shh pathway-induced cell motility and invasiveness is largely independent of EMT. Whether Shh pathway activation induces EMT in normal thyrocytes and in well differentiated thyroid tumor cell lines remains to be determined.

Todardo et al. [17] reported that c-Met is highly activated in thyroid cancer stem cells, and that inhibition of c-Met by gene knockdown significantly inhibits thyroid cancer stem cell motility and invasion. Our earlier study showed that SW1736 cells contain a much higher percent of thyroid cancer stem-like cells than that in KAT-18 cells [23]. In our present study, we found that cyclopamine had little effect on c-Met phosphorylation in KAT-18 cells but inhibited c-Met phosphorylation in SW1736 cells (Figure 3). Moreover, we found that c-Met inhibitor III had little effect on the migration and invasion of untransfected KAT18 cells but inhibited the migration and invasions of Gli1transfected KAT-18 cells (Figure 4). Lack of inhibitory effect by cyclopamine on c-Met phosphorylation and lack of inhibitory effect by the Met kinase inhibitor III on cell migration and invasion was likely due to lower c-Met expression (Figure 6) and lower percent of cancer stem-like cells in KAT-18 cells than that in SW1736 cells [23]. In contrast, we found that stable suppression of Shh expression in Shh-miRNA-transfected KAT-18 cells significantly decreased c-Met expression, whereas stable overexpression of Glil significantly increased c-Met expression. Differential effect of cyclopamine and Shh knockdown on c-Met and AKT activation as well as on E-cadherin expression could be due to the off-target effect of CP. Alternatively, stable suppression of the Shh pathway by gene knockdown may lead to c-Met and E-cadherin promoter demethylation.

In addition to its effect on EMT, Snail is capable of stimulating tumor cell motility and invasion by inducing the expression of matrix metalloproteinases (MMP). For example, Snail overexpression in pancreatic ductal adenocarcinomas increases tumor cell invasiveness by increasing the expression of MMP-14 and membrane type (MT)-1-MMP [41, 42]. Activation of the Shh pathway induces the expression of MMP-9 in pancreatic cancer cell lines [37] and MT1-MMP expression in ovarian cancer cell lines [5]. Our recent and present studies demonstrated the ability of the Shh pathway to regulate Snail expression, and Snail suppression inhibited KAT-18 and SW1736 cell motility and invasiveness. Thus, the Shh pathway may also stimulate thyroid tumor cell motility and invasiveness by Snail-induced proteinase expression (Figure 7).

In summary, our present study showed that the 
Shh pathway was involved in activating the PI-3 kinase pathway and promoting the motility and invasiveness of two anaplastic thyroid cancer cell lines. We further showed that Snail and the activation of the PI-3 kinase pathway as well as c-Met played a critical role in mediating the Shh pathway-induced thyroid tumor cell motility and invasiveness. The inhibitors of the Shh pathway may have potential to be developed as novel anti-thyroid cancer drugs to control anaplastic thyroid CSC-like phenotype, tumor invasiveness and metastasis.

\section{MATERIALS AND METHODS}

\section{Cell lines and plasmid DNA}

WRO82, KAT-18 and SW1736 cell lines were authenticated and reported earlier [19, 23]. Characteristics and stable transfection of KAT-18 cells with miRNAs targeting Shh and Glil or with Glil overexpression have been recently reported [23]. The passages of the three cell lines used in our studies are: WRO82 between 80-95 passages; KAT-18 between 28 and 40 passages; SW1736 between 10-25 passages.

\section{Cell motility and chemoinvasion assay}

Single cell suspensions of KAT-18 and SW1736 cells were prepared and seeded in the top chamber of the 24-well Transwell inserts $\left(2 \times 10^{4} /\right.$ well) in serum-free medium supplemented with $0.1 \%$ bovine serum albumin. For the chemoinvasion assay, the inserts were pre-coated with Matrigel (100 $\mu \mathrm{g} /$ well; Roche Diagnostics Corp., Indianapolis, IN). The Transwell inserts were placed in a 24-well companion plate filled with $0.75 \mathrm{ml}$ of complete RPMI1640 medium containing 10\% fetal bovine serum. To analyze the effect of PI-3 kinase and c-Met inhibitors on cell motility and invasive potential, LY294002 (10 $\mu \mathrm{M})$ (Cell Signaling Technology, Danvers, MA), or c-Met inhibitor III (5 $\mu \mathrm{M})$ (EMD Millipore, Billerica, MA) was added into both top and bottom chambers. After incubation for $24 \mathrm{~h}$, the cells in the inner side of top chamber were removed by wiping with cotton swabs. The effect of cyclopamine (LC Laboratories, Woburn, MA), a Smo inhibitor, and GANT61 (Sigma, St. Louis, MO), a Gli1 inhibitor, on cell motility and invasiveness were similarly conducted. Snail knockdown was carried out as described [23] and similarly analyzed for its effect on thyroid tumor cell motility and invasiveness, The cells that migrated through uncoated or Matrigel-coated polyethylene terephthalate (PET) membranes were stained with a Diff-Quik kit (Mercedes Medical, Sarasota, FL). The membrane was sliced out, mounted on slides and sealed with the mounting media. The cells in five random fields (10X) were counted under a light microscope.

\section{Western blot}

Cell lysates were prepared as described [23] and analyzed for the expression of AKT, phospho-AKT ${ }^{\mathrm{S} 473}$, c-Met tyrosine phosphorylation at Y1230/1234/1235, Gli1, Snail, Slug, Vimentin, and E-cadherin (Cell Signaling Biotechnology, Inc., Danvers, MA). For loading control, $\beta$-actin was detected by a mouse monoclonal antibody (Santa Cruz Biotechnology Inc., San Diego, CA). The density of the bands was analyzed by using an Image-J software and normalized by actin. The results were the mean \pm standard deviation from three independent experiments.

\section{Statistical analysis}

The differences in the number of the cells migrating through the PET membrane between different treatment groups were statistically analyzed by using an unpaired Student $t$ test. A $p$ value of $<0.05$ was considered statistically significant. All statistics was performed with SigmaPlot 11 software (Systat Software, Inc, San Jose, CA).

\section{ACKNOWLEDGMENTS}

We thank Drs. Guy J. F. Juillard (University of California at Los Angeles) and Kenneth B. Ain (University of Kentucky Medical Center, Lexington, KY) for kindly providing three thyroid tumor cell lines, Dr. Tsutomu Kume (Northwestern University Feinberg School of Medicine) for pcDNA/Gli1 plasmid.

\section{FUNDING}

This work was supported in part by the ThyCa Foundation (X.X.) and Rush Dean's Fellowship (A.W.), a start-up fund(X. Xu) from College of Veterinary Medicine, Yangzhou University; and the Priority Academic Program Development of Jiangsu Higher Education Institutions.

\section{CONFLICTS OF INTEREST}

The authors declare that there is no conflict of interest that could be perceived as prejudicing the impartiality of the research reported.

\section{Editorial note}

This paper has been accepted based in part on peerreview conducted by another journal and the authors' response and revisions as well as expedited peer-review in Oncotarget. 


\section{REFERENCES}

1. Hooper JE, and Scott MP. Communicating with Hedgehogs. Nat Rev Mol Cell Biol. 2005; 6:306-17.

2. Taipale J, and Beachy PA. The Hedgehog and Wnt signalling pathways in cancer. Nature. 2001; 411:349-54.

3. van den Brink GR. Hedgehog signaling in development and homeostasis of the gastrointestinal tract. Physiol Rev. 2007; 87:1343-75.

4. Tam WL, and Weinberg RA. The epigenetics of epithelialmesenchymal plasticity in cancer. Nat Med. 2013; 19:143849.

5. Liao X, Siu MK, Au CW, Wong ES, Chan HY, Ip PP, Ngan HY, and Cheung AN. Aberrant activation of hedgehog signaling pathway in ovarian cancers: effect on prognosis, cell invasion and differentiation. Carcinogenesis. 2009; 30:131-40.

6. Joost S, Almada LL, Rohnalter V, Holz PS, Vrabel AM, Fernandez-Barrena MG, McWilliams RR, Krause M, Fernandez-Zapico ME, and Lauth M. GLI1 inhibition promotes epithelial-to-mesenchymal transition in pancreatic cancer cells. Cancer research. 2012; 72:88-99.

7. Stecca B, Mas C, Clement V, Zbinden M, Correa R, Piguet V, Beermann F, and Ruiz IAA. Melanomas require HEDGEHOG-GLI signaling regulated by interactions between GLI1 and the RAS-MEK/AKT pathways. Proceedings of the National Academy of Sciences of the United States of America. 2007; 104:5895-900.

8. Ramaswamy B, Lu Y, Teng KY, Nuovo G, Li X, Shapiro $\mathrm{CL}$, and Majumder S. Hedgehog signaling is a novel therapeutic target in tamoxifen-resistant breast cancer aberrantly activated by PI3K/AKT pathway. Cancer research. 2012; 72:5048-59.

9. Riobo NA, Lu K, Ai X, Haines GM, and Emerson CP, Jr. Phosphoinositide 3-kinase and Akt are essential for Sonic Hedgehog signaling. Proceedings of the National Academy of Sciences of the United States of America. 2006; 103:4505-10.

10. Yoo YA, Kang MH, Lee HJ, Kim BH, Park JK, Kim HK, Kim JS, and Oh SC. Sonic hedgehog pathway promotes metastasis and lymphangiogenesis via activation of Akt, EMT, and MMP-9 pathway in gastric cancer. Cancer research. 2011; 71:7061-70.

11. Riobo NA, and Manning DR. Pathways of signal transduction employed by vertebrate Hedgehogs. The Biochemical journal. 2007; 403:369-79.

12. Singh RR, Cho-Vega JH, Davuluri Y, Ma S, Kasbidi F, Milito C, Lennon PA, Drakos E, Medeiros LJ, Luthra R, et al. Sonic hedgehog signaling pathway is activated in ALKpositive anaplastic large cell lymphoma. Cancer research. 2009; 69:2550-8.

13. Chen JS, Huang XH, Wang Q, Huang JQ, Zhang LJ, Chen XL, Lei J, and Cheng ZX. Sonic hedgehog signaling pathway induces cell migration and invasion through focal adhesion kinase/AKT signaling-mediated activation of matrix metalloproteinase (MMP)-2 and MMP-9 in liver cancer. Carcinogenesis. 2013; 34:10-9.

14. Sharma N, Nanta R, Sharma J, Gunewardena S, Singh KP, Shankar S, and Srivastava RK. PI3K/AKT/mTOR and sonic hedgehog pathways cooperate together to inhibit human pancreatic cancer stem cell characteristics and tumor growth. Oncotarget. 2015; 6:32039-60. doi: 10.18632/ oncotarget.5055.

15. Srivastava RK, Kaylani SZ, Edrees N, Li C, Talwelkar $\mathrm{SS}, \mathrm{Xu} \mathrm{J}$, Palle K, Pressey JG, and Athar M. GLI inhibitor GANT-61 diminishes embryonal and alveolar rhabdomyosarcoma growth by inhibiting Shh/AKTmTOR axis. Oncotarget. 2014; 5:12151-65. doi: 10.18632/ oncotarget. 2569.

16. O'Neill JP, and Shaha AR. Anaplastic thyroid cancer. Oral Oncol. 2013; 49:702-6.

17. Todaro M, Iovino F, Eterno V, Cammareri P, Gambara G, Espina V, Gulotta G, Dieli F, Giordano S, De Maria R, et al. Tumorigenic and metastatic activity of human thyroid cancer stem cells. Cancer research. 2010; 70:8874-85.

18. Ma R, Minsky N, Morshed SA, and Davies TF. Stemness in Human Thyroid Cancers and Derived Cell Lines: The Role of Asymmetrically Dividing Cancer Stem Cells Resistant to Chemotherapy. The Journal of Clinical Endocrinology \& Metabolism. 2014; 99:E400-E9.

19. Xu X, Ding H, Rao G, Arora S, Saclarides CP, Esparaz J, Gattuso P, Solorzano CC, and Prinz RA. Activation of the Sonic Hedgehog pathway in thyroid neoplasms and its potential role in tumor cell proliferation. Endocr Relat Cancer. 2012; 19:167-79.

20. Hinterseher U, Wunderlich A, Roth S, Ramaswamy A, Bartsch DK, Hauptmann S, Greene BH, Fendrich V, and Hoffmann S. Expression of hedgehog signalling pathway in anaplastic thyroid cancer. Endocrine. 2014; 45:439-47.

21. Bohinc B, Michelotti G, and Diehl AM. Hedgehog signaling in human medullary thyroid carcinoma: a novel signaling pathway. Thyroid. 2013; 23:1119-26.

22. Bian XH, Sun H, Xue H, Zhang G, Zhang CH, Liu XL, Su $\mathrm{J}$, and Li SJ. Expression and clinical significance of Shh/ Gli-1 in papillary thyroid carcinoma. Tumour Biol. 2014.

23. Heiden KB, Williamson AJ, Doscas ME, Ye J, Wang Y, Liu D, Xing M, Prinz RA, and Xu X. The sonic hedgehog signaling pathway maintains thyroid cancer stem cell selfrenewal by inducing Snail expression Journal of Clinical Endocrinology and Metabolism. 2014; 99(E2178-87.

24. Qiao M, Sheng S, and Pardee AB. Metastasis and AKT activation. Cell Cycle. 2008; 7:2991-6.

25. Chui MH. Insights into cancer metastasis from a clinicopathologic perspective: Epithelial-Mesenchymal Transition is not a necessary step. International journal of cancer Journal international du cancer. 2013; 132:1487-95.

26. Ji Z, Mei FC, Xie J, and Cheng X. Oncogenic KRAS activates hedgehog signaling pathway in pancreatic 
cancer cells. The Journal of biological chemistry. 2007; 282:14048-55.

27. Nucera C, Lawler J, and Parangi S. BRAF(V600E) and microenvironment in thyroid cancer: a functional link to drive cancer progression. Cancer research. 2011; 71:241722.

28. Nucera C, Porrello A, Antonello ZA, Mekel M, Nehs MA, Giordano TJ, Gerald D, Benjamin LE, Priolo C, Puxeddu E, et al. B-Raf(V600E) and thrombospondin-1 promote thyroid cancer progression. Proceedings of the National Academy of Sciences of the United States of America. 2011; 107:10649-54.

29. Knauf JA, Sartor MA, Medvedovic M, Lundsmith E, Ryder M, Salzano M, Nikiforov YE, Giordano TJ, Ghossein RA, and Fagin JA. Progression of BRAF-induced thyroid cancer is associated with epithelial-mesenchymal transition requiring concomitant MAP kinase and TGFbeta signaling. Oncogene. 2011; 30:3153-62.

30. Sadow PM, Priolo C, Nanni S, Karreth FA, Duquette M, Martinelli R, Husain A, Clohessy J, Kutzner H, Mentzel $\mathrm{T}$, et al. Role of BRAFV600E in the first preclinical model of multifocal infiltrating myopericytoma development and microenvironment. Journal of the National Cancer Institute. $2014 ; 106$.

31. Wei L, and Xu Z. Cross-signaling among phosphinositide-3 kinase, mitogen-activated protein kinase and sonic hedgehog pathways exists in esophageal cancer. International journal of cancer Journal international du cancer. 2011; 129:275-84.

32. Fan F, Gray MJ, Dallas NA, Yang AD, Van Buren G, 2nd, Camp ER, and Ellis LM. Effect of chemotherapeutic stress on induction of vascular endothelial growth factor family members and receptors in human colorectal cancer cells. Mol Cancer Ther. 2008; 7:3064-70.

33. Jensen K, Patel A, Hoperia V, Larin A, Bauer A, and Vasko V. Dynamic changes in E-cadherin gene promoter methylation during metastatic progression in papillary thyroid cancer. Exp Ther Med.1:457-62.

34. Rocha AS, Soares P, Seruca R, Maximo V, MatiasGuiu X, Cameselle-Teijeiro J, and Sobrinho-Simoes M. Abnormalities of the E-cadherin/catenin adhesion complex in classical papillary thyroid carcinoma and in its diffuse sclerosing variant. J Pathol. 2001; 194:358-66.

35. Smith JA, Fan CY, Zou C, Bodenner D, and Kokoska MS. Methylation status of genes in papillary thyroid carcinoma. Arch Otolaryngol Head Neck Surg. 2007; 133:1006-11.

36. Xue G, and Hemmings BA. PKB/Akt-dependent regulation of cell motility. Journal of the National Cancer Institute. 2013; 105:393-404.

37. Yoo YA, Kang MH, Kim JS, and Oh SC. Sonic hedgehog signaling promotes motility and invasiveness of gastric cancer cells through TGF-beta-mediated activation of the ALK5-Smad 3 pathway. Carcinogenesis. 2008; 29:480-90.

38. Li X, Deng W, Lobo-Ruppert SM, and Ruppert JM. Gli1 acts through Snail and E-cadherin to promote nuclear signaling by beta-catenin. Oncogene. 2007; 26:4489-98.

39. Li X, Deng W, Nail CD, Bailey SK, Kraus MH, Ruppert $\mathrm{JM}$, and Lobo-Ruppert SM. Snail induction is an early response to Gli1 that determines the efficiency of epithelial transformation. Oncogene. 2006; 25:609-21.

40. Feldmann G, Dhara S, Fendrich V, Bedja D, Beaty R, Mullendore M, Karikari C, Alvarez H, Iacobuzio-Donahue C, Jimeno A, et al. Blockade of hedgehog signaling inhibits pancreatic cancer invasion and metastases: a new paradigm for combination therapy in solid cancers. Cancer research. 2007; 67:2187-96.

41. Shields MA, Dangi-Garimella S, Krantz SB, Bentrem DJ, and Munshi HG. Pancreatic cancer cells respond to type I collagen by inducing snail expression to promote membrane type 1 matrix metalloproteinase-dependent collagen invasion. The Journal of biological chemistry. 2011; 286:10495-504.

42. Shields MA, Dangi-Garimella S, Redig AJ, and Munshi HG. Biochemical role of the collagen-rich tumour microenvironment in pancreatic cancer progression. The Biochemical journal. 2012; 441:541-52. 